\title{
Procalcitonin in clinical practice: from diagnosis of sepsis to antibiotic therapy
}

\author{
Gabriele Cioni, ${ }^{1}$ Jessica Canini, ${ }^{2}$ Filippo Pieralli ${ }^{3}$ \\ ${ }^{1}$ Emergency Department, SS Cosma and Damiano Pescia Hospital, USL Toscana Centro, Pescia (PT); ${ }^{2}$ San Luca Hospital, \\ USL Toscana Nord Ovest, Lucca; ${ }^{3}$ AOU Careggi, Florence, Italy
}

\begin{abstract}
A diagnostic algorithm that allows for the rapid identification of sepsis and possibly guides the appropriate antimicrobial therapy application is the cornerstone to obtaining effective treatment and better results. The use of emerging surrogate markers could significantly improve clinical practice, but the validity and clinical utility have been proved only for very few of them, and their availability in clinical routine is limited. For this purpose, numerous scientific evidence has indicated procalcitonin as a marker linked to sepsis and its evolution. This review aims to retrace the main evidence relating to the use of procalcitonin in sepsis. We analyzed the primary studies in the literature and the existing meta-analysis evaluating the behavior of procalcitonin as a marker of bacterial sepsis, its prognostic power, and its ability to influence antibiotic therapy. Recent evidence has suggested that procalcitonin could be an efficient marker for diagnosing sepsis and its therapeutic management in many types of patients. The choice of the appropriate timing to initiate and suspend antibiotic therapy, with obvious clinical advantages, the favorable effects could also include reducing health costs, both avoiding the administration of inappropriate antibiotic therapies, and reducing the duration of hospitalization. Moreover, limited studies reported high procalcitonin levels in coronavirus disease 2019 patients with a worse prognosis. Despite the considerable evidence in favor of the potential of procalcitonin as an index for managing septic patients, there are conflicting data that deserve specific and detailed studies.
\end{abstract}

\section{Introduction}

Serious bacterial infections and their sequels are still a major problem, burdened by a high mortality rate in hospitals; for this reason, ${ }^{1,2}$ a diagnostic algorithm that allows for the rapid identification of sepsis, and possibly guides the appropriate application of antimicrobial therapy, is the cornerstone to obtaining effective treatment and better results.

Correspondence: Gabriele Cioni, Emergency Department, SS Cosma and Damiano Pescia Hospital, USL Toscana Centro, Pescia (PT), Italy.

E-mail: gabrielec.83@gmail.com

Key words: COVID-19; procalcitonin; sepsis; antimicrobial therapy.

Conflict of interests: the authors declare no potential conflict of interests.

Received for publication: 29 November 2020.

Accepted for publication: 30 November 2020.

This work is licensed under a Creative Commons Attribution NonCommercial 4.0 License (CC BY-NC 4.0).

${ }^{\circ}$ Copyright: the Author(s), 2021

Licensee PAGEPress, Italy

Italian Journal of Medicine 2021; 15:7-16

doi:10.4081/itjm.2021.1438
Critical elements for a rapid diagnosis of sepsis are the clinical pattern, imaging results, and biohumoral markers of systemic inflammatory response. The ideal standard for the definition would be the definite isolation of causative microorganisms through positive cultures and/or molecular identification. Unfortunately, the delay in microbiology response and the false-negative rate results make it challenging. ${ }^{3}$

The use of emerging surrogate markers could significantly improve clinical practice, but the validity and clinical utility have been proved only for very few of them, and their availability in clinical routine is limited. ${ }^{4}$

Reliable bio-marker desirable features should be the diagnostic accuracy, management simplicity, prognostic power, and the ability to predict and monitor clinical response to a therapeutic intervention, ${ }^{5}$ and affordable costs.

In septic conditions, a complex host immune response, activated by pathogen-related antigens, enhances the production and the release of several inflammatory mediators into the bloodstream, including cytokines and vasoactive molecules, receptor bio-markers, and coagulative factors. Precursors and mature products of these mediators could be useful surrogate markers to improve the diagnosis and assess disease gravity.

Different researchers based on considerable evidence have proposed that procalcitonin possesses adequate potency in predicting bacterial etiology of the infectious process. Procalcitonin is a precursor of calci- 
tonin, whose production increases during infection due to the overexpression of the CALC 1 gene. The main pathway of procalcitonin secretion ${ }^{6}$ is represented by the neuroendocrine cells of the intestine and lung tissue within 4 hours, and its concentration can increase nearly 1000 -fold after a severe bacterial infection; based on similar evidence, it was suggested that there might be a link between blood levels of procalcitonin (PCT) and the severity of the infection. PCT has a good kinetic profile compared to C-reactive protein (CRP); its rise is more rapid, and a reduced 7 renal function does not significantly modify blood concentrations. Such behavior would make procalcitonin an ideal marker, both diagnostic and for therapeutic and prognostic management.

\section{Aim}

The aim of this review is to retrace the main evidence relating to the use of procalcitonin in sepsis.

\section{Methods of research}

We analyzed the main studies in the literature and the existing meta-analysis evaluating the role of procalcitonin in diagnosing bacterial sepsis, its prognostic power in the course of sepsis, and in its ability to influence antibiotic therapy.

The discussion was conducted according to essential points such as the role of PCT as a diagnostic marker of sepsis, prognostic index, and guiding tool of clinicaltherapeutic management; furthermore for each point the studies in favor and against were evaluated.

\section{Procalcitonin for diagnosis of bacterial sepsis}

The link between procalcitonin and its metabolites with bacterial infections was initially observed in a study carried out in 1993; the authors observed an increase in procalcitonin levels during sepsis. Furthermore, these early observations had suggested a possible role as a direct marker of patient prognosis, significantly increasing in more severe infections. ${ }^{6-8}$

Subsequent studies had enjoyed greater accuracy with which serum PCT concentrations were detected in future years, providing even more accurate analyses.

The debate on the diagnostic role of PCT was thus enriched, particularly with the publication of the first prospective studies.

Several studies provided results in favor of procalcitonin utility. ${ }^{10-29}$

In particular, among them, Wanner et al. ${ }^{11}$ measured the PCT concentrations at the time of admission, demonstrating that these were higher in case of diagnosis of sepsis or severe multiorgan dysfunction syndrome related to influenza.

However, there are also other prospective studies ${ }^{30-36}$ that have shown contrary results to the previous ones, with negative results regarding the role of PCT as a diagnostic marker.

In recent years, various authors compared PCT with other well-established indicators of inflammation and infection, such as $\mathrm{CRP}^{37}$ and high-sensitivity CRP, ${ }^{38}$ presepsin, ${ }^{37}$ neutrophil CD64 ${ }^{39}$ lactate levels,${ }^{40}$ white blood cells and neutrophil count, ${ }^{41,42}$ interleukin (IL)- $6^{43}$.

Meisner et al. ${ }^{43}$ investigated the relationship between PCT and inflammatory markers, such as CRP, in 40 subjects with systemic inflammation complicated with multiple organ failure over 15 days. Investigators reported that PCT levels of non-surviving patients significantly increased after the fourth day, whereas CRP was not different between surviving and non-surviving subjects; these findings supported that measurement of PCT concentrations during multiple organ dysfunction syndrome could describe the illness course better than CRP.

Further evidence was provided in a prospective cohort study conducted by Muller, ${ }^{44}$ on 101 critically ill medical patients. The research aimed to compare the diagnostic power of PCT to other markers of inflammation, such as CRP, IL-6, and lactate levels, in the case of sepsis.

Serum procalcitonin levels proved to be the most efficient marker for identifying patients suffering from sepsis, compared to other variables. Moreover, a cut-off equal to $1 \mathrm{ng} / \mathrm{mL}$ showed the best power (sensitivity $89 \%$ and specificity $94 \%$ ) for diagnosis. In addition to selecting septic patients over other critically ill patients, the elevated serum PCT concentrations were predictive of poor prognosis.

Similar data were provided by Ibrahim et al. ${ }^{45}$ The group of researchers conducted a prospective cohort study on critically ill patients (73) admitted to a medical-surgical intensive care unit to identify the pattern of blood parameters that faithfully identified sepsis. Standard blood parameters (blood cell count and CRP) did not have the same diagnostic capability as PCT.

Furthermore, confirming data from other studies, the PCT cut-off $>1 \mathrm{ng} / \mathrm{mL}$ had the greatest diagnostic and prognostic accuracy (75\% diagnostic accuracy, $72 \%$ specificity, and $76 \%$ sensitivity).

When procalcitonin was tested in specific clinical settings, such as populations of community-acquired pneumonia, to evaluate both the potential benefits of diagnostic speed and accuracy and optimize clinical management in lower respiratory tract infections, the authors have obtained conflicting results. ${ }^{46-48}$

A relevant proposal has been provided by Muller et al., suggesting a different behavior of serum procalcitonin levels between bacterial rather than viral pneumonia.

Analyzing a population of patients with a suspected clinical pattern for lower respiratory tract infection, the authors reported that procalcitonin had shown diagnostic 
superiority over other markers in recognizing bacterial pneumonia. In detail, PCT showed greater diagnostic accuracy [area under the curve (AUC), 0.88 (0.840.93)], compared to high sensitivity CRP [AUC, 0.76 (0.69-0.83); $\mathrm{P}<0.001]$ and total white blood cell count [AUC, 0.69 (0.62-0.77); $\mathrm{P}<0.001$ ].

Additionally, higher PCT levels were reported for bacteremia, even compared to high sensitivity CRP blood levels, white blood cell counts, and body temperature. In confirmation of the previous data, which wanted PCT as a prognostic marker, Muller et al. showed that PCT identified patients suffering from pneumonia with the worst course. ${ }^{49}$

Further insights into the diagnostic accuracy of PCT and its ability to identify patients with high mortality were provided by The Diagnostic and Prognostic Utility of Procalcitonin in Patients Presenting to the Emergency Department with Dyspnea (DPUP) study. ${ }^{50}$

The investigated population is made up of symptomatic patients for dyspnea who went to the emergency room. Of the total of 453,30 patients presented a clinical pattern compatible with isolated pneumonia (6.6\%), while for another 30 (6.6\%), dyspnea resulted from a clinical pattern compatible with exacerbation of heart failure secondary to pneumonia. In both groups, pneumonia was associated with elevated PCT levels, compared to the other causes of dyspnea; PCT also provided a good diagnostic capability of pneumonia compared to dyspnea from other causes.

Similarly, other studies showed that the value of 0.10 $\mathrm{ng} / \mathrm{mL}$ was recognized as the optimal cut-off (sensitivity $80 \%$ and specificity $77 \%$, respectively) for the diagnosis of pneumonia. Interesting data concern the increase in the diagnostic power of PCT when associated with other markers. Furthermore, PCT is shown to be able to implement the differential diagnosis of dyspnea, discriminating between cardiac and infectious causes.

A study of similar design is the BACH study, conducted by Maisel et al.$^{51}$ It is a prospective, international study conducted on a population of 1641 subjects enrolled in the emergency room for the onset of dyspnea.

PCT has proved to be a powerful aid in the differential diagnosis of dyspnea, considering its high ability to identify pneumonia. Furthermore, an antibiotic therapy algorithm guided by PCT, could prove to be an adequate choice precisely in cases of diagnostic uncertainty to optimize its use. In particular, if patients showed high PCT $(>0.21 \mathrm{ng} / \mathrm{mL})$ or low PCT levels $(<0.05 \mathrm{ng} / \mathrm{mL})$, the prognosis was worse or better, if not treated with antibiotics $(\mathrm{P}=0.046)$, or treated $(\mathrm{P}=0.049)$, respectively. Accordingly, other studies showed an improvement in the accuracy of diagnosis and severity assessment of community acquired pneumonia for the approaches using PCT. ${ }^{46,52,53}$

Moreover, in the context of the diagnosis of pneumonia, contrary to the studies presented so far, Le Ben et al. have shown evidence that PCT is not an adequate marker. In detail, the study in question is part of a subanalysis related to a prospective multicenter study that evaluates the role of thoracic $\mathrm{CT}$ in the diagnosis of pneumonia in a population of 200 patients. ${ }^{52}$

Another clinical context in which PCT has been extensively evaluated is the one concerning abdominal infections, particularly the surgical patient. Elevated PCT levels have been found in subjects with abdominal infections, in both medical and surgical patients. In particular, its high predictive value for sepsis arising after abdominal surgery procedures was identified. ${ }^{54}$

Data conflict in cardiac surgery. In detail, in a study conducted on a population of 400 surgical patients, elevated PCT levels were strongly suggestive of post-cardiac surgical infection. ${ }^{26}$ Also, in a population of cardiac surgery patients, elevated PCT values were more predictive of a septic shock than CRP. ${ }^{25}$ On the other hand, the results of Dorge et al. were negative, which did not show a statistically significant relationship between PCT and sepsis. ${ }^{32}$

Sepsis of renal origin has also been the subject of investigation. In an analysis conducted on 49 patients with pyelonephritis complicating renal lithiasis, the predictive strength of PCT was confirmed statistically significant even after multivariate analysis. The analysis included different variables, such as blood cell count, renal function index, inflammatory markers, assessed as a marker of sepsis; at receiver operating characteristic (ROC) analysis, PCT showed the highest accuracy (AUC: 0.929 vs 0.822 ) and the cut-off value of $0.52 \mathrm{ng} / \mathrm{mL}$, presented the best diagnostic power. ${ }^{55}$

The authors of the PBC-PCI study published relevant data. In particular, researchers conducted a retrospective analysis of data concerning 422 subjects enrolled in the emergency room for the suspicion of infection. The diagnostic accuracy of PCT in predicting blood culture positivization was statistically significant. The cut-off value of $0.5 \mathrm{ng} / \mathrm{mL}$ was associated with a positivization rate of the cultures of $34.0 \% .^{56}$

In the context of medical patients with multiple comorbidities, for which a systemic fungal superinfection may be hypothesized, the data of a retrospective casecontrol study (64 cases vs 128 controls) stand out, in which the authors demonstrated a negative predictive value of PCT $>2.5 \mathrm{ng} / \mathrm{mL}$ for identification of Candida species from blood cultures [AUC of $0.76(0.68-0.84)$ $95 \%$ confidence interval $(\mathrm{CI})] \cdot{ }^{57}$

\section{Meta-analyses on the diagnostic role of procalcitonin}

Since 2006, meta-analyses evaluated both the diagnostic role of serum concentrations of PCT and the use of PCT-based algorithms in optimizing therapies in septic patients, providing conflicting results..$^{58-67}$ The 
main meta-analyses that provided results in favor of the usefulness of PCT as a diagnostic marker are discussed in more detail below. ${ }^{58-66}$

First, the meta-analysis by Uzzan et al. ${ }^{58}$ was conducted on a large population, for a total of 1826 patients from intensive care or predominantly surgical settings, suffering from sepsis of different severity. The control group consisted of 1545 patients with inflammatory response syndrome. The published data, although it must be taken into account that medical and immunosuppressed patients were excluded from the analysis, are statistically in favor of PCT as a marker of all the various clinical degrees of sepsis, even more so than CRP.

In the analysis conducted, a broad correction lacks multiple confounding factors; in particular, no subanalysis takes into account the patient's clinical context and site of infection.

Studies investigating the use of PCT-based strategies $^{61-64}$ reported positive results.

In another relevant meta-analysis conducted by Wacker et al. ${ }^{65}$ on a population of 3244 patients derived from 30 different clinical studies, authors suggested that PCT may have adequate diagnostic power for sepsis, particularly in critically ill patients. However, a correct clinical contextualization for an adequate interpretation of data is fundamental. This limitation was due essentially to the heterogeneity of the studies analyzed.

In a recent meta-analysis ${ }^{66}$ the role of CRP and PCT was compared in the optimization of differential fever diagnostics by analyzing data from 17 different studies. High values of both markers were found in patients with infection probably of bacterial origin, compared to the group with a fever of unknown origin; however, the sensitivity of PCT was greater than that of CRP, showing itself to be a more reliable marker, as can be easily seen from the ROC curves, for PCT [0.82 (95\% CI, 0.78-0.86)] and CRP, respectively [0.78 (95\% CI, 0.70-0.78)].

The extensive meta-analysis by Schuetz et al. ${ }^{67}$ was conducted on a total population of 6708 derived from 26 different multicenter international studies to evaluate PCT levels for multiple endpoints concerning the presence of acute airways infection.

The utility of PCT has been tested not only in relation to its diagnostic capacity; in particular, it was investigated whether PCT levels could optimize therapeutic choices, guide patient management in the event of therapeutic failure, and, furthermore, identify patients at greater risk for poor prognosis.

In fact, the group of patients in which the diagnostic and therapeutic management was conducted based on PCT levels showed a better prognosis than the control group, whose path was conducted according to standard protocol. The use of PCT as an index to es- tablish the duration of antimicrobial therapy also made it possible to optimize the duration [5.7 vs 8.1 days (95\% CI -2.71 to -2.15$), \mathrm{P}<0.0001]$ and thus reduce the iatrogenic adverse effects [ $16 \%$ vs $22 \%$, adjusted odds ratio (OR) 0.68 (95\% CI 0.57 to 0.82), $\mathrm{P}<0.0001]$, compared to the control group.

However, although the evidence listed so far is substantially in favor of the role of PCT in the management of the infectious patient, data published by Tang et al. ${ }^{59}$ are in contrast.

The data published by this group of researchers provided results of non-superiority of PCT compared to a standard marker panel, showing both low sensitivity and low diagnostic power. In particular, the analysis was conducted on a large population derived from 18 different studies, having however excluded from analyses all the cases concerning abdominal sepsis, pancreatitis, meningitis or septic shock; low values of sensitivity and specificity, equal to $71 \%$ (95\% CI 67-76), and an area under the curve of 0.78 (95\% CI 0.73-0.83) were reported.

Only Jones et al. reported inconclusive results. ${ }^{60}$

\section{Prognostic role of procalcitonin in sepsis}

The potential of PCT as a prognostic marker, i.e., capable of identifying patients at risk of an inauspicious course of infectious disease or with a clinical pattern of relevant severity since presentation to the emergency department triage, has been widely debated.

In particular, since the nineties, various investigations have been carried out in this regard, which have provided conflicting results.

Most of the prospective studies, , $, 10,11-17,18-29,44,68-80$ showed a statistically significant correlation between serum procalcitonin concentrations and disease severity or outcome.

Prospective data on 246 patients with post-surgical abdominal infection confirmed a relationship between elevated PCT levels and mortality, with a statistically significant difference for PCT levels in patients not surviving compared to those with a better prognosis $(\mathrm{P}<0.01) .^{70}$

In the TRIAGE study, ${ }^{71}$ a recent observational, prospective, cohort, multicenter study, a PCT-based approach identified patients with worse prognosis (AUC 0.75), rapid clinical deterioration requiring admission to intensive care (AUC 0,62) or critical presentation since admission to the emergency room (AUC 0.58). These results were unaffected by other clinical variables, including age and different comorbidities.

When assessed during severe sepsis or septic shock, the kinetics of PCT assays in the first 72 hours after admission was considered a useful prognostic marker, rather than isolated measurements at patient 
entry, ${ }^{72}$ in particular, the percentage change in PCT between hospitalization and 72 hours and between 24 hours after admission and the following 72 hours, was an adequate mortality index at 30 days. ${ }^{72}$ Confirming these data, Becker et al. ${ }^{73}$ also reported that serial measurements of PCT and PCT kinetics were more useful in determining disease severity and prognosis $^{73}$ than absolute isolated samples; furthermore, the role of borderline or early-collected PCT values was downsized.

A PCT-based algorithm proposed in a work by De Jong et al..$^{74}$ provided new evidence of the utility of PCT regarding mortality in comparison with standard care. In more detail, the authors conducted a prospective intervention trial on 1575 critically ill patients admitted to the Intensive Care Unit (ICU); published results provided consistent evidence that clinical management monitoring PCT values in progress were associated with greater diagnostic accuracy and optimization in terms of therapeutic efficacy and safety. In particular, this approach allowed the early reduction of antibiotic therapy in $71 \%$ of patients [5 days (3-9) versus 7 days (4-11)], with the consequent reduction of adverse effects; moreover, the therapy was aimed at suspected cases, to increase its effectiveness with a consequent reduction in mortality at 28 days and 1 year.

By contrast, other prospective studies by Sudhir $e t$ al., ${ }^{35}$ Whang et al. ${ }^{81}$ Selberg et al.,${ }^{68}$ Castelli et al. ${ }^{69}$ and Dahaba et al. ${ }^{82}$ found low or no correlation between serum concentrations of PCT and prognosis in sepsis.

\section{Meta-analysis and prognostic role of procalcitonin}

In recent years, several studies ${ }^{75-89}$ have investigated whether PCT levels were associated with different mortality endpoints in the septic patient. The several data available have highlighted that high PCT concentrations are associated with a worse prognosis, with a relative risk ranging from 1.38 to 24.62 .

In particular, it was found that PCT changes over time are statistically significant in terms of mortality. ${ }^{90}$

Based on these data, PCT clearance was investigated in nine different studies, ${ }^{91-98}$ for a total population of 868 patients. Subjects who had reduced PCT clearance at subsequent controls had a high risk of poor prognosis, as evidenced by the aggregate relative risk (RR) for mortality 3.05 (95\% CI, 2.35-3.95). These studies are burdened by numerous limitations that do not fully clarify the potential of PCT as a prognostic marker. First, the accuracy of PCT could not be adequately estimated to predict death in emergency room patients; furthermore, the inability to perform subgroup analyses, in particular based on different admission categories or different infection sites, did not allow to de- cline the potential of PCT in these different areas; as the last element, a cut-off value was not provided.

Similar data were obtained from a recent metaanalysis conducted on a large population of $3994 \mathrm{pa}-$ tients from 23 studies, in which both high PCT concentrations [2.60 (95\% CI, 30)], and a reduced PCT clearance [RR was 3.05 (95\% CI, 2.35-3.95)] are adequate markers of all-cause mortality in ongoing sepsis. ${ }^{99}$

\section{Procalcitonin and antibiotic therapy}

The appropriate use of antibiotics is fundamental for ensuring the efficiency of treatment, ${ }^{100}$ avoiding the development of drug resistance, ${ }^{101}$ and improving patient safety. ${ }^{102}$ Several pieces of evidence suggested the role of procalcitonin in targeting the correct use of antimicrobials in clinical therapy, ${ }^{103}$ in comparison with other biomarkers. ${ }^{104}$

The role of serum PCT concentrations in monitoring for complications of sepsis has been evaluated in several prospective trials in the last 20 years.

In particular, the studies that have proposed to evaluate the relationship between PCT and management of antibiotic therapy have questioned whether this marker was able to indicate both when to start antibiotic therapy, its suspension and, therefore, its optimal duration.

In a study conducted on 165 patients hospitalized in a medical setting for community-acquired infections, a cut-off of $0.4 \mathrm{ng} / \mathrm{mL}$ showed the best negative predictive value $(98.8 \%)$ compared to standard inflammatory markers. ${ }^{105-108}$

In a very select group of patients, such as those suffering from chronic obstructive pulmonary disease exacerbation, a decision algorithm based on PCT, aimed at identifying exacerbations on an infectious basis, managed to contain antibiotic prescriptions ( $40 \%$ vs $72 \%$, respectively; $\mathrm{P}<0.0001$ ), but without limiting the patient's recovery. Instead, an improvement was observed in terms of adverse effects related to therapy and inappropriate prescriptions, compared to a standard approach. ${ }^{48}$

Accordingly, Schroeder et al. ${ }^{109}$ reported similar evidence. The authors elaborated a prospective randomized case-control study, conducted on 27 patients admitted to surgical intensive care, in which antibiotic therapy was started after positive culture tests, while PCT levels guided discontinuation of therapy with severe sepsis. ${ }^{109}$ As in other studies, the PCT-led approach made it possible to reduce the duration of antibiotic therapy for the benefit of clinical safety and by optimizing the use of drug therapy, without significant differences in mortality.

In addition to the benefits in terms of clinical outcome and mortality, a rationalization of the use of antibiotic therapy has also shown a positive impact on 
costs, expressed as a shorter length of hospitalization and less waste of pharmacological resources. ${ }^{107}$

However, caution is a must, considering other data in which an apparently targeted therapy did not improve the mortality rates of the populations examined. ${ }^{108,109}$

To confirm this, a study conducted on 1200 critically ill patients admitted to intensive care for different clinical reasons reported that a reduction in antimicrobial therapy, based on PCT, led to numerous complications, recorded in terms of organ failure, and an increased length of hospitalization and mortality. ${ }^{110,111}$

Other studies have also conservatively confirmed the benefit alone in reducing the duration of antibiotic therapy, and finally decreasing total hospital spending, cutting down unnecessary tests, procedures, and admission length, but without significantly affecting patient survival. ${ }^{112,113}$

\section{Procalcitonin and COVID-19}

The trend of procalcitonin levels in patients with severe acute respiratory syndrome-related coronavirus 2 infection has been recently investigated. In a retrospective study of 140 patients, divided into mild and severe clinical presentations, the latter had higher procalcitonin levels. However, these results are burdened by the smallness of the sample. The authors proposed as an explanation for this relationship that the most severe clinical presentation is associated with bacterial superinfection. ${ }^{114}$ The results of a meta-analysis are in agreement with these data. ${ }^{115} \mathrm{~A}$ ferritin/procalcitonin score was proposed as a diagnostic tool to differentiate COVID-19 from bacterial pneumonia in a case-control study. However, further studies are needed to clarify the real diagnostic scope ${ }^{116}$ (Table 11,20,23,26,27,32,70,108,117-122).

Table 1. Different clinical uses of procalcitonin and related studies.

\begin{tabular}{|c|c|c|c|}
\hline Authors & Study population & Setting & Study parameters \\
\hline Wanner et al., $2000^{11}$ & 133 & $\begin{array}{l}\text { Emergency } \\
\text { Department and } \\
\text { Trauma Intensive } \\
\text { Care Unit }\end{array}$ & $\begin{array}{l}\text { PCT was considered an early indicator of septic complication in trauma } \\
\text { patients }\end{array}$ \\
\hline Reith et al., $2000^{70}$ & 246 & $\begin{array}{l}\text { Surgical Intensive } \\
\text { Care Unit }\end{array}$ & $\begin{array}{l}\text { PCT as an indicator of complications, such as peritonitis, in septic } \\
\text { patients, s/p abdominal surgery }\end{array}$ \\
\hline Dorge et al., $2003^{32}$ & 80 & $\begin{array}{l}\text { Surgical Intensive } \\
\text { Care Unit }\end{array}$ & PCT was an early predictor of postoperative complications \\
\hline Benoist et al., $1998^{20}$ & 21 & $\begin{array}{l}\text { Surgical Intensive } \\
\text { Care Unit }\end{array}$ & PCT identified sepsis in trauma patients \\
\hline Rothenburger et al., $1999^{23}$ & 59 & $\begin{array}{l}\text { Surgical Intensive } \\
\text { Care Unit }\end{array}$ & PCT indicated sepsis in postoperative cardiac patients \\
\hline Baykut et al., 2000²6 & 400 & $\begin{array}{l}\text { Surgical Intensive } \\
\text { Care Unit }\end{array}$ & PCT was a predictor of sepsis in postoperative cardiac patients \\
\hline Boeken et al., $2000^{27}$ & 74 & $\begin{array}{l}\text { Surgical Intensive } \\
\text { Care Unit }\end{array}$ & PCT predicted sepsis in postoperative cardiac patients \\
\hline Meisner et al., $2002^{117}$ & 208 & $\begin{array}{l}\text { Surgical Intensive } \\
\text { Care Unit }\end{array}$ & PCT as an indicator of sepsis in postoperative cardiac patients \\
\hline Hensler et al., $2003^{118}$ & 138 & $\begin{array}{l}\text { Trauma Intensive } \\
\text { Care Unit and } \\
\text { Surgical Intensive } \\
\text { Care Unit }\end{array}$ & PCT as an early indicator of sepsis in major trauma patients \\
\hline Mokart et al., $2005^{119}$ & 50 & $\begin{array}{l}\text { Surgical Intensive } \\
\text { Care Unit }\end{array}$ & PCT was considered an indicator of postoperative infectious complication \\
\hline Reith et al., $1998^{120}$ & 70 & $\begin{array}{l}\text { Surgical Intensive } \\
\text { Care Unit }\end{array}$ & PCT as an early indicator of postoperative infectious complication \\
\hline Castelli et al., $2006^{121}$ & 255 & $\begin{array}{l}\text { Medical and } \\
\text { Surgical Intensive } \\
\text { Care Unit }\end{array}$ & PCT was used in monitoring for sepsis in ICU patients \\
\hline Lavrentieva et al., $2007^{108}$ & 43 & $\begin{array}{l}\text { Burn Intensive } \\
\text { Care Unit }\end{array}$ & PCT as an early predictor of septic complication in burnpatients \\
\hline Novotny et al., $2009^{122}$ & 104 & $\begin{array}{l}\text { Surgical Intensive } \\
\text { Care Unit }\end{array}$ & $\begin{array}{l}\text { PCT as an indicator for determining if repeat laparotomy is needed } \\
\text { inpatients with prior laparotomy for infective source }\end{array}$ \\
\hline
\end{tabular}

PCT, procalcitonin; ICU, Intensive Care Unit. 


\section{Conclusions}

Recent evidence has suggested the role of procalcitonin in the rapid detection of septic conditions and in the management of antimicrobial therapy in different clinical settings. Significantly, the favorable effects of such approach led to an improvement in clinical outcomes; moreover, a reduction of health costs was obtained avoiding the administration of inappropriate antibiotic therapies and reducing the duration of hospitalization. However, there are conflicting data, which deserve further study and analysis.

\section{References}

1. Angus DC, Linde-Zwirble WT, Lidicker J, et al. Epidemiology of severe sepsis in the United States: analysis of incidence, outcome, and associated costs of care. Crit Care Med 2001;29:1303-10.

2. Martin GS, Mannino DM, Eaton S, Moss M. The epidemiology of sepsis in the United States from 1979 through 2000. N Engl J Med 2003;348:1546-54.

3. Marshall JC, Reinhart K. Biomarkers of sepsis. Crit Care Med 2009;37:2290-8.

4. Liu Y, Hou J, Li Q, et al. Biomarkers for diagnosis of sepsis in patients with systemic inflammatory response syndrome: a systematic review and meta-analysis. Springerplus 2016;2091.

5. Biomarkers Definitions Working Group. Biomarkers and surrogate endpoints: preferred definitions and conceptual framework. Clin Pharmacol Ther 2001;69:89-95.

6. Maruna P, Nedělníková K, Gürlich R. Physiology and genetics of procalcitonin. Physiol Res 2000;49:57-61.

7. Dandona P, Nix D, Wilson MF, et al. Procalcitonin increase after endotoxin injection in normal subjects. J Clin Endocrinol Metab 1994;79:1605-8.

8. Assicot M, Gendrel D, Carsin H, et al. High serum procalcitonin concentrations in patients with sepsis and infection. Lancet 1993;341:515-8.

9. Giamarellos-Bourboulis E, Grecka A, Scarpa N, et al. Procalcitonin: A marker to clearly differentiate systemic inflammatory inflammatory response syndrome and sepsis in the critically ill patient? Intensive Care Med 2002;28:1351-6.

10. Harbarth S, Holeckova K, Froidevaux C, et al. Diagnostic value of procalcitonin, interleukin-6, and interleukin8 in critically ill patients admitted with suspected sepsis. Am J Respir Crit Care Med 2001;164:396-402.

11. Wanner G, Keel M, Steckholzer U, et al. Relationship between procalcitonin plasma levels and severity of injury, sepsis, organ failure, and mortality in injured patients. Crit Care Med 2000;28:950-7.

12. Brunkhorst F, Wegscheider K, Forycki Z, et al. Procalcitonin for early diagnosis and differentiation of SIRS, sepsis, severe sepsis, and septic shock. Intensive Care Med 2000;26:S148-52.

13. Balci C, Sungurtekin H, Gürses E, et al. Usefulness of procalcitonin for diagnosis of sepsis in the intensive care unit. Crit Care 200;7:85-90.

14. Luzzani A, Polati E, Dorizzi R, et al. Comparison of pro- calcitonin and C-reactive protein as markers of sepsis. Crit Care Med 2003;31:1737-41.

15. Endo S, Aikawa N, Fujishima S, et al. Usefulness of procalcitonin serum level for the discrimination of severe sepsis from sepsis: A multicenter prospective study. J Infect Chemother 2008;14:244-9.

16. Tsangaris I, Plachouras D, Kavatha D, et al. Diagnostic and prognostic value of procalcitonin among febrile critically ill patients with prolonged ICU stay. BMC Infect Dis 2009;9:213.

17. Meynaar I, Droog W, Batstra M, et al. In critically ill patients, serum procalcitonin is more useful in differentiating between sepsis and SIRS than CRP, Il-6, or LBP. Crit Care Res Pract 2011;2011:594-645.

18. Al-Nawas B, Krammer I, Shah P. Procalcitonin in diagnosis of severe infections. Eur J Med Res 1996;1:331-3.

19. De Werra I, Jaccard C, Betz Corradin S, et al. Cytokines, nitrite/nitrate, soluble tumor necrosis factor receptors, and procalcitonin concentrations: Comparisons in patients with septic shock, cardiogenic shock, and bacterial pneumonia. Crit Care Med 1997;25:607-13.

20. Benoist J, Mimoz O, Assicot M, et al. Serum procalcitonin, but not C-reactive protein, identifies sepsis in trauma patients. Clin Chem 1998;44:1778-9.

21. Whang K, Steinwald P, White J, et al. Serum calcitonin precursors in sepsis and systemic inflammation. J Clin Endocrinol Metab 1998;83:3296-301.

22. Bossink A, Groeneveld A, Thijs L. Prediction of microbial infection and mortality in medical patients with fever: Plasma procalcitonin, neutrophilic elastase-alphaantitrypsin, and lactoferrin compared with clinical variables. Clin Infect Dis 1999;29:398-407.

23. Rothenburger M, Markewitz A, Lenz T, et al. Detection of acute phase response and infection. The role of procalcitonin and C-reactive protein. Clin Chem Lab Med 1999;37:275-9.

24. Adamik B, Kubler-Kielb J, Golebiowska B, et al. Effect of sepsis and cardiac surgery with cardiopulmonary bypass on plasma level of nitric oxide metabolites, neopterin, and procalcitonin: Correlation with mortality and postoperative complications. Intensive Care Med 2000;26:1259-67.

25. Aouifi A, Piriou V, Bastien O, et al. Usefulness of procalcitonin for diagnosis of infection in cardiac surgical patients. Crit Care Med 2000;28:3171-6.

26. Baykut D, Schulte-Herbruggen J, Krian A. The value of procalcitonin as an infection marker in cardiac surgery. Eur J Med Res 2000;5:530-6.

27. Boeken U, Feindt P, Micek M, et al. Procalcitonin (PCT) in cardiac surgery: Diagnostic value in systemic inflammatory response syndrome (SIRS), sepsis and after heart transplantation (HTX). Cardiovasc Surg 2000;8:550-4.

28. Cheval C, Timsit J, Garrouste-Orgeas M, et al. Procalcitonin (PCT) is useful in predicting the bacterial origin of an acute circulatory failure in critically ill patients. Intensive Care Med 2000;26:S153-8.

29. Oberhoffer M, Russwurm S, Bredle D, et al. Discriminative power of inflammatory markers for prediction of tumor necrosis factor-a and interleukin-6 in ICU patients with systemic inflammatory response syndrome (SIRS) or sepsis at arbitrary time points. Intensive Care Med 2000;26:S170-4.

30. Suprin E, Camus C, Gacouin A, et al. Procalcitonin: a 
valuable indicator of infection in a medical ICU? Intensive Care Med 2000;26:1232-8.

31. Ugarte H, Silva E, Mercan D, et al. Procalcitonin used as a marker of infection in the intensive care unit. Crit Care Med 1999;27:498-504.

32. Dorge H, Schondube FA, Dorge P, et al. Procalcitonin is a valuable prognostic marker in cardiac surgery but not specific for infection. Thorac Cardiovasc Surg 2003;51:322-6.

33. Ruokonen E, Ilkka L, Niskanen M, Takala J. Procalcitonin and neopterin as indicators of infection in critically ill patients. Acta Anaesthesiol Scand 2002;46:398-404.

34. Baumgarten R, Pequeriaux N, Van Puyenbroek MJE, Speelberg B. Diagnosis of sepsis by procalcitonin. Ned Tijdschr Klin Chem 2002;27:32-35.

35. Sudhir U, Venkatachalaiah R, Kumar TA, et al. Significance of serum procalcitonin in sepsis. Indian J Crit Care Med 2011;15:1-5.

36. Gibot S, Kolopp-Sarda M, Bene M. Plasma level of a triggering receptor expressed on myeloid cells-1: Its diagnostic accuracy in patients with suspected sepsis. Ann Intern Med 2004;141:9-15.

37. Wu CC, Lan HM, Han ST, et al. Comparison of diagnostic accuracy in sepsis between presepsin, procalcitonin, and C-reactive protein: a systematic review and meta-analysis. Ann Intensive Care 2017;7:91.

38. Zhang H, Wang X, Zhang Q, et al. Comparison of procalcitonin and high-sensitivity $\mathrm{C}$-reactive protein for the diagnosis of sepsis and septic shock in the oldest old patients. BMC Geriatr 2017;17:173.

39. Qin DJ, Tang ZS, Chen SL, et al. [Value of combined determination of neutrophil CD64 and procalcitonin in early diagnosis of neonatal bacterial infection]. Zhongguo Dang Dai Er Ke Za Zhi 2017;19:872-6. [in Chinese].

40. Ljungström L, Pernestig AK, Jacobsson G, et al. Diagnostic accuracy of procalcitonin, neutrophil-lymphocyte count ratio, C-reactive protein, and lactate in patients with suspected bacterial sepsis. PLoS One 2017; 12:e181704.

41. Karon BS, Tolan NV, Wockenfus AM, et al. Evaluation of lactate, white blood cell count, neutrophil count, procalcitonin and immature granulocyte count as biomarkers for sepsis in emergency department patients. Clin Biochem. 2017 May 25. pii: S0009-9120(17)30220-5.

42. Heredia-Rodríguez M, Bustamante-Munguira J, Lorenzo M, et al. Procalcitonin and white blood cells, combined predictors of infection in cardiac surgery patients. J Surg Res 2017;212:187-94.

43. Meisner M, Tschaikowsky K, Palmaers T, Schmidt J. Comparison of procalcitonin (PCT) and C-reactive protein (CRP) plasma concentrations at different SOFA scores during the course of sepsis and MODS. Crit Care 1999;3:45-50.

44. Müller B, Becker K, Schächinger H, et al. Calcitonin precursors are reliable markers of sepsis in a medical intensive care unit. Crit Care Med 2000;28:977-83.

45. Nargis W, Ibrahim MD, Ahamed BU. Procalcitonin versus C-reactive protein: usefulness as biomarker of sepsis in ICU patient. Int J Crit Illn Inj Sci 2014;4:195-9.

46. Walsh TL, DiSilvio BE, Hammer C, et al. Impact of procalcitonin guidance with an educational program on management of adults hospitalized with pneumonia. Am J Med 2017 Sep 22. pii: S0002-9343(17)30940-3.
47. He C, Wang B, Li D, Xu H, Shen Y.Performance of procalcitonin in diagnosing parapneumonic pleural effusions: A clinical study and meta-analysis. Medicine (Baltimore) 2017;96:e7829.

48. Çolak A, Y1lmaz C, Toprak B, Aktoğu S. Procalcitonin and $\mathrm{CRP}$ as biomarkers in discrimination of communityacquired pneumonia and exacerbation of COPD. J Med Biochem 2017;36:122-6.

49. Müller B, Harbarth S, Stolz D, et al. Diagnostic and prognostic accuracy of clinical and laboratory parameters in community-acquired pneumonia. BMC Infect Dis 2007;7:10.

50. Alba GA, Truong QA, Gaggin HK, et al. Diagnostic and prognostic utility of procalcitonin in patients presenting to the emergency department with dyspnea. Am J Med 2016;129:96-104.

51. Maisel A, Neath SX, Landsberg J, et al. Use of procalcitonin for the diagnosis of pneumonia in patients presenting with a chief complaint of dyspnoea: results from the BACH (Biomarkers in Acute Heart Failure) trial. Eur J Heart Fail 2012;14:278-86.

52. Le Bel J, Hausfater P, Chenevier-Gobeaux C, et al.; ESCAPED study group. Diagnostic accuracy of C-reactive protein and procalcitonin in suspected community-acquired pneumonia adults visiting emergency department and having a systematic thoracic CT scan. Crit Care 2015; 19:366.

53. Müller B, Harbarth S, Stolz D, et al. Diagnostic and prognostic accuracy of clinical and laboratory parameters in community-acquired pneumonia. BMC Infect Dis 2007;7:10.

54. Domínguez-Comesaña E, Estevez-Fernández SM, López-Gómez V, et al. Procalcitonin and C-reactive protein as early markers of postoperative intra-abdominal infection in patients operated on colorectal cancer. Int J Colorectal Dis 2017;32:1771-4.

55. Ko YH, Ji YS, Park SY, et al. Procalcitonin determined at emergency department as an early indicator of progression to septic shock in patient with sepsis associated with ureteral calculi. Int Braz J Urol 2016;42:270-6.

56. Arai T, Kumasaka K, Nagata K, et al. Prediction of blood culture results by measuring procalcitonin levels and other inflammatory biomarkers. Am J Emerg Med 2014;32:330-3.

57. Pieralli F, Corbo L, Torrigiani A, et al. Usefulness of procalcitonin in differentiating Candida and bacterial blood stream infections in critically ill septic patients outside the intensive care unit. Intern Emerg Med 2017; 12:629-35

58. Uzzan B. Procalcitonin as a diagnostic test for sepsis in critically ill adults and after surgery or trauma: a systematic review and metaanalysis. Crit Care Med 2006;34:1996-2003.

59. Tang BM, Eslick GD, Craig JC, et al. Accuracy of procalcitonin for sepsis diagnosis in critically ill patients: systematic review and metaanalysis. Lancet Infect Dis 2007;7:210-7.

60. Jones AE, Fiechtl JF, Brown MD, et al. Procalcitonin test in the diagnosis of bacteremia: a meta-analysis. Ann Emerg Med 2007;50:34-41.

61. Kopterides P, Siempos II, Tsangaris I, et al. Procalcitonin-guided algorithms of antibiotic therapy in the intensive care unit: a systematic review and meta-analysis 
of randomized controlled trials. Crit Care Med 2010;38:2229-41.

62. Heyland D, Johnson A, Reynolds S, Muscedere J. Procalcitonin for reduced antibiotic exposure in the critical care setting: A systematic review and an economic evaluation. Crit Care Med 2011;39:1792-9.

63. Schuetz P, Chiappa V, Briel M, Greenwald JL. Procalcitonin algorithms for antibiotic therapy decisions: A systematic review of randomized controlled trials and recommendations for clinical algorithms. Arch Intern Med 2011;171:1322-31.

64. Wilke M, Grube R, Bodmann K. The use of a standardized PCT-algorithm reduces costs in intensive care in septic patients - A DRG-based simulation model. Eur J Med Res 2011;16:543-8.

65. Wacker C, Prkno A, Brunkhorst FM, Schlattmann P. Procalcitonin as a diagnostic marker for sepsis: a systematic review and meta-analysis. Lancet Infect Dis 2013;13:426-35.

66. Hu L, Shi Q, Shi M, et al. Diagnostic Value of PCT and CRP for detecting serious bacterial infections in patients with fever of unknown origin: a systematic review and meta-analysis. Appl Immunohistochem Mol Morphol 2017;25:e61-9.

67. Schuetz P, Wirz Y, Sager R, et al. Effect of procalcitoninguided antibiotic treatment on mortality in acute respiratory infections: a patient level meta-analysis. Lancet Infect Dis 2018;18:95-107.

68. Selberg O, Hecker H, Martin M, et al. Discrimination of sepsis and systemic inflammatory response syndrome by determination of circulating plasma concentrations of procalcitonin, protein complement $3 \mathrm{a}$, and interleukin-6. Crit Care Med 2000;28:2793-8.

69. Castelli G, Pognani C, Meisner M, et al. Procalcitonin and $\mathrm{C}$-reactive protein during systemic inflammatory response syndrome, sepsis and organ dysfunction. Crit Care 2004;8:R234-42.

70. Reith H, Mittelko“tter U, Wagner R, et al. Procalcitonin (PCT) in patients with abdominal sepsis. Intensive Care Med 2000;26:S165-9.

71. Sager R, Wirz Y, Amin D, et al. Are admission procalcitonin levels universal mortality predictors across different medical emergency patient populations? Results from the multi-national, prospective, observational TRIAGE study. Clin Chem Lab Med 2017;55:1873-80.

72. Pieralli F, Vannucchi V, Mancini A, et al. procalcitonin kinetics in the first 72 hours predicts 30-day mortality in severely ill septic patients admitted to an Intermediate Care Unit. J Clin Med Res 2015;7:706-13.

73. Becker K, Snider R, Nylen E. Procalcitonin assay in systemic inflammation, infection, and sepsis: Clinical utility and limitations. Crit Care Med 2008;36:941-52.

74. de Jong E, van Oers JA, Beishuizen A, et al. Efficacy and safety of procalcitonin guidance in reducing the duration of antibiotic treatment in critically ill patients: a randomised, controlled, open-label trial. Lancet Infect Dis 2016;16:819-27.

75. Adamik B, Kübler-Kielb J, Golebiowska B, et al. Effect of sepsis and cardiac surgery with cardiopulmonary bypass on plasma level of nitric oxide metabolites, neopterin, and procalcitonin: correlation with mortality and postoperative complications. Intensive Care Med 2000;26:1259-67.
76. Meng FS, Su L, Tang YQ, et al. Serum procalcitonin at the time of admission to the ICU as a predictor of shortterm mortality. Clin Biochem 2009;42:1025-31.

77. Yin Q, Liu B, Chen Y, et al. The role of soluble thrombomodulin in the risk stratification and prognosis evaluation of septic patients in the emergency department. Thromb Res 2013;132:471-6.

78. Suberviola B, Castellanos-Ortega A, Ruiz Ruiz A, et al. Hospital mortality prognostication in sepsis using the new biomarkers suPAR and proADM in a single determination on ICU admission. Intensive Care Med 2013;39:1945-52.

79. Clec'h C, Fosse JP, Karoubi P, et al. Differential diagnostic value of procalcitonin in surgical and medical patients with septic shock. Crit Care Med 2006;34:102-7.

80. Li Z, Wang H, Liu J, et al. Serum soluble triggering receptor expressed on myeloid cells-1 and procalcitonin can reflect sepsis severity and predict prognosis: a prospective cohort study. Mediators Inflamm 2014;2014:641039.

81. Masson S, Caironi P, Spanuth E, et al. Presepsin (soluble CD14 subtype) and procalcitonin levels for mortality prediction in sepsis: data from the Albumin Italian Outcome Sepsis trial. Crit Care 2014;18:R6.

82. Yaroustovsky M, Plyushch M, Popov D, et al. Prognostic value of endotoxin activity assay in patients with severe sepsis after cardiac surgery. J Inflamm (Lond) 2014;10:8.

83. Feng L, Zhou X, Su LX, et al. Clinical significance of soluble hemoglobin scavenger receptor CD163 (sCD163) in sepsis, a prospective study. PLoS One 2012; 7:e38400.

84. Jain S, Sinha S, Sharma SK, et al. Procalcitonin as a prognostic marker for sepsis: a prospective observational study. BMC Res Notes 2014;7:458.

85. Dahaba AA, Hagara B, Fall A, et al. Procalcitonin for early prediction of survival outcome in postoperative critically ill patients with severe sepsis. $\mathrm{Br} \mathrm{J}$ Anaesth 2006;97:503-8.

86. Magrini L, Travaglino F, Marino R, et al. Procalcitonin variations after Emergency Department admission are highly predictive of hospital mortality in patients with acute infectious diseases. Eur Rev Med Pharmacol Sci 2013;17:133-42.

87. Savva A, Raftogiannis M, Baziaka F, et al. Soluble urokinase plasminogen activator receptor (suPAR) for assessment of disease severity in ventilator-associated pneumonia and sepsis. J Infect 2011;63:344-50.

88. Kenzaka T, Okayama M, Kuroki S, et al. Use of a semiquantitative procalcitonin kit for evaluating severity and predicting mortality in patients with sepsis. Int J General Med 2012;5:483-8.

89. Giamarellos-Bourboulis EJ, Tsangaris I, Kanni T, et al. Procalcitonin as an early indicator of outcome in sepsis: a prospective observational study. J Hosp Infect 2011;77:58-63.

90. Liu D, Su L, Han G, et al. Prognostic value of procalcitonin in adult patients with sepsis: a systematic review and meta-analysis. PLoS One 2015;10:e0129450.

91. Tschaikowsky K, Hedwig-Geissing M, Braun GG, Radespiel-Troeger M. Predictive value of procalcitonin, interleukin-6, and C-reactive protein for survival in postoperative patients with severe sepsis. J Crit Care 2011;26:54-64.

92. Schuetz P, Maurer P, Punjabi V, et al. Procalcitonin decrease over 72 hours in US critical care units predicts fatal outcome in sepsis patients. Crit Care 2013;17:R115. 
93. Mat Nor MB, Md Ralib A. Procalcitonin clearance for early prediction of survival in critically ill patients with severe sepsis. Crit Care Res Pract 2014;2014:819034.

94. Ruiz-Rodríguez JC, Caballero J, Ruiz-Sanmartin A, et al. Usefulness of procalcitonin clearance as a prognostic biomarker in septic shock. A prospective pilot study. Med Intens 2014;36:475-80.

95. Suberviola B, Castellanos-Ortega A, González-Castro A, et al. Prognostic value of procalcitonin, C-reactive protein and leukocytes in septic shock. Med Intens 2012;36:177-84.

96. Karlsson S, Heikkinen M, Pettilä V, et al. Predictive value of procalcitonin decrease in patients with severe sepsis: A prospective observational study. Crit Care 2010;14:R205.

97. García de Guadiana-Romualdo LM, Rebollo-Acebes S, Esteban-Torrella $P$, et al. Prognostic value of lipopolysaccharide binding protein and procalcitonin in patients with severe sepsis and septic shock admitted to intensive care. Med Intens 2015;39:207-12.

98. Guan J, Lin Z, Lue H. Dynamic change of procalcitonin, rather than concentration itself, is predictive of survival in septic shock patients when beyond 10 ng/mL. Shock 2011;36:570-4.

99. Liu D, Su L, Han G, et al. Prognostic value of procalcitonin in adult patients with sepsis: a systematic review and meta-analysis. PLoS One 2015;10:e0129450.

100. Liew YX, Chlebicki MP, Lee W, et al. Use of procalcitonin (PCT) to guide discontinuation of antibiotic use in an unspecified sepsis is an antimicrobial stewardship program (ASP). Eur J Clin Microbiol Infect Dis 2011;30:853-5.

101. Larson E. Community factors in the development of antibiotic resistance. Annu Rev Public Health 2007;28: 435-47.

102. Scott F, James B, Ryan F, et al. Vital signs: improving antibiotic use among hospitalized patients. Mob Mort Wkly Rep 2014;63:194-200.

103. Lieberman JM. Appropriate antibiotic use and why it is important: the challenges of bacterial resistance. Pediatr Infect Dis J 2003;22:1143-51.

104. Simon P, Milbrandt EB, Emlet LL. PCT-guided antibiotics in severe sepsis. Crit Care 2008;12:309.

105. Chirouze C, Schuhmacher H, Rabaud C, et al. Lowserum procalcitonin level accuracy predicts the absence of bacteraemia in adult patients with acute fever. Clin Infect Dis 2002;35:156-61.

106. Schroeder S, Hochreiter M, Koehler T, et al. Procalcitonin (PCT )-guided algorithm reduces length of antibiotic treatment in surgical intensive care patients with severe sepsis: results of a prospective randomized study. Langenbeck's Arch Surg 2009;394:221-6.

107. Kip MM, Kusters R, Ijzerman J, Steuten MA. PCT algorithm for discontinuation of antibiotic therapy is a cost-effective way to reduce antibiotic exposure in adult intensive care patients with sepsis. J Med Econ 2015;18:944-53.

108. Lavrentieva A, Kontou P, Soulountsi V, et al. Implementation of a procalcitonin-guided algorithm for an- tibiotic therapy in the burn intensive care unit. Ann Burns Fire Disasters 2015;28:163-70.

109. Nobre V, Harbarth S, Graf JD, et al. Use of procalcitonin to shorten antibiotic treatment duration in septic patients. Am J Resp Crit Care Med 2008;177:498-505.

110. Jensen J, Hein L, Lundgren B, et al. Procalcitoninguided interventions against infections to increase early appropriate antibiotics and improve survival in the intensive care unit: A randomized trial. Crit Care Med 2011;39:2048-58

111. Jensen J, Lundgren B, Hein L, et al. The Procalcitonin And Survival Study (PASS) - a randomised multi-center investigator- initiated trial to investigate whether daily measurements biomarker procalcitonin and proactive diagnostic and therapeutic responses to abnormal Procalcitonin levels, can improve survival in intensive care unit patients. Calculated sample size (target population): 1000 patients. BMC Infect Dis 2008;8:91.

112. Wacker C, Prkno A, Brunkhorst FM, Schlattmann P. Procalcitonin as a diagnostic marker for sepsis: a systematic review and meta-analysis. Lancet Infect Dis 2013;13:426-35.

113. Balk RA, Kadri SS, Cao Z, et al. Effect of procalcitonin testing on health-care utilization and costs in critically ill patients in the United States. Chest 2017;151:23-33.

114. Liu F, Li L, Xu MD, et al. Prognostic value of interleukin-6, C-reactive protein, and procalcitonin in patients with COVID-19. J Clin Virol 2020;127:104370.

115. Lippi G, Plebani M. Procalcitonin in patients with severe coronavirus disease 2019 (COVID-19): A metaanalysis. Clin Chim Acta 2020;505:190-1. Published online 2020 Mar 4. doi: 10.1016/j.cca.2020.03.004.

116. Gharamti AA, Mei F, Jankousky KC, et al. Diagnostic utility of a ferritin-to-procalcitonin ratio to differentiate patients with COVID-19 from those with bacterial pneumonia: a multicenter study. Version 1. medRxiv. Preprint. 2020 Oct 22. doi: 10.1101/2020.10.20.20216309

117. Meisner M, Rauschmayer C, Schmidt J, et al. Early increase of procalcitonin after cardiovascular surgery in patients with postoperative complications. Intensive Care Med 2002;28:1094-102.

118. Hensler T, Sauerland S, Lefering R, et al. The clinical value of procalcitonin and neopterin in predicting sepsis and organ failure after major trauma. Shock 2003;20:420-6.

119. Mokart D, Merlin M, Sannini A, et al. Procalcitonin, interleukin 6 and systemic inflammatory response syndrome (SIRS): Early markers of postoperative sepsis after major surgery. Br J Anaesth 2005;94:767-73.

120. Reith H, Mittelko"tter U, Debus E, et al. Procalcitonin in early detection of postoperative complications. Dig Surg 1998;15:260-5.

121. Castelli G, Pognani C, Cita M, et al. Procalcitonin, Creactive protein, white blood cells and SOFA score in ICU: Diagnosis and monitoring of sepsis. Minerva Anestesiol 2006;72:69-80.

122. Novotny A, Emmanuel K, Hueser N, et al. Procalcitonin ratio indicates successful surgical treatment of abdominal sepsis. Surgery 2009;145:20-6. 